\title{
ShaoYao decoction ameliorates colitis-associated colorectal cancer by downregulating proinflammatory cytokines and promoting epithelial-mesenchymal transition
}

Xiaochang Lin ${ }^{1 \dagger}$, Zhiyong $\mathrm{Yi}^{1 \dagger}$, Jianxin Diao ${ }^{2}$, Meng Shao ${ }^{2}$, Liang Zhao ${ }^{3}$, Hongbing Cai ${ }^{2}$, Qin Fan ${ }^{2}$, Xueqing Yao ${ }^{4^{*}}$ and Xuegang Sun ${ }^{1,2^{*}}$

\begin{abstract}
s
Background: Shaoyao decoction (SYD) is a traditional Chinese medicine prescription formulated by Liu Wan-Su, a master of traditional Chinese medicine in Jin-Yuan Dynasty. SYD is effective in treating ulcerative colitis. Paeonol, a component of SYD, inhibits colorectal cancer (CRC) cell proliferation and induces CRC cell apoptosis. In this study, azoxymethane (AOM)/dextran sodium sulfate (DSS)-induced colitis-associated CRC (CaCRC) model and CRC cell lines were used to examine the effects of SYD on CRC in vivo and in vitro.

Methods: A translational medicine strategy based on phytomics quality control was adopted. Liquid chromatography was employed for the chemical characterization and chemical fingerprinting of SYD. Protein expression and macrophage existence were determined by immunohistochemistry and western blot. Serum cytokines were quantified by Luminex assay.

Results: AOM/DSS-induced caCRC phenotypically resembled human caCRC. SYD significantly increased the survival rate of the mice, ameliorated the general well-being of the mice, and reduced the incidence and multiplicity of colonic neoplasms. SYD inhibited epithelial-mesenchymal transition (EMT), as indicated by upregulated epithelia cadherin and downregulated neuronal cadherin, fibronectin, vimentin, and transcription factor Snail. SYD reduced the expression levels of serum interleukin $1 \beta$, interleukin-6, tumor necrosis factor $a$, tumor-associated macrophages, and p65. These results showed that SYD can attenuate proinflammatory cytokines and inhibit EMT.
\end{abstract}

Conclusions: SYD ameliorates caCRC by suppressing inflammation and inhibiting EMT. SYD might be an alternative therapy for caCRC.

Keywords: Shaoyao decoction, Colitis, Colorectal cancer, Epithelial-mesenchymal transition, Snail, Tumor associated macrophages, Proinflammatory cytokines

\footnotetext{
* Correspondence: yjb9211@21cn.com; sxg_smu@126.com

${ }^{\dagger}$ Equal contributors

${ }^{4}$ Department of Gastrointestinal Surgery, Guangdong General Hospital,

Guangzhou 510120, China

'Department of Traditional Chinese Medicine, Nanfang Hospital, Southern

Medical University, Guangzhou 510515, China

Full list of author information is available at the end of the article
} 


\section{Introduction}

Approximately 142,820 (9\%) and 50,830 (9\%) new cancer cases and deaths of colorectal cancer (CRC) were reported in the US in 2013, respectively [1]. CRC is the third most common cancer in men and the second in women worldwide [2]. Ulcerative colitis, familial adenomatous polyposis, and hereditary nonpolyposis colon cancer syndrome are the three highest risk groups for developing CRC. In a metaanalysis based on 116 studies, the overall prevalence of colorectal cancer in patients with ulcerative colitis was $3.7 \%$. The risk of colorectal cancer increases by $8 \%$ in 20 years and by $18 \%$ in 30 years [3]. The pathogenesis of colorectal cancer in patients with ulcerative colitis is triggered by inflammation-dependent mechanisms [4]. Furthermore, ameliorating inflammation can control inflammation-mediated reactive oxygen species, microsatellite instability, telomere shortening, and chromosomal instability [4].

Shaoyao decoction (SYD) is a canonical Chinese medicine prescription formulated by Liu Wan-Su in "Plain Questions - anthology on proper therapy for Qi disorder and pathogenesis to save life" in Jin-Yuan dynasty (AD 1186). SYD is commonly used to treat various inflammatory bowel diseases by clearing heat and damp, removing stasis and toxin in the intestine [5]. SYD is effective in ameliorating the major manifestations of ulcerative colitis, such as hematochezia, abdominal pain, diarrhea, and mucosal defense impairment [6,7]. SYD enhances mucous cell proliferation, decreases exfoliated mucosal cell proliferation, and prevents lamina propria edema and neutrophil infiltration [8]. SYD also exerts anti-inflammatory effects that can decrease the expression of intercellular adhesion molecule 1 (ICAM-1) and tumor necrosis factor $\alpha$ (TNF- $\alpha$ ) and increase the expression of interleukin (IL)-10 in colon tissues [9]. Paeonol, the primary phenolic component in Radix Paeoniae Alba (Shaoyao), reduces HT29 cell proliferation by downregulating cyclooxygenase- 2 and upregulating p27 [10]. Paeonol induces LoVo cell apoptosis by increasing intracellular calcium concentration [11]. However, whether or not SYD can prevent colitisassociated CRC (caCRC) remains elusive.

The epithelial-mesenchymal transition (EMT) serves important functions in the formation of body plan and the differentiation of multiple tissues [12]. EMT is a process in which epithelial cells trans-differentiate and acquire invasive mesenchymal phenotype. Clinical analysis [13] and animal experiments [14] demonstrated that EMT contributes to the loss of intestinal epithelial cells; thus, EMT is recognized as a major contributor to the pathogenesis of inflammatory bowel diseases. Transforming growth factor $\beta$ (TGF- $\beta$ ), TNF- $\alpha$, and nuclear factor $\kappa B$ (NF-кB) participate in inflammation development; these factors are also crucial for the initiation of EMT [15]. In the present study, the functions of EMT in azoxymethane
$(\mathrm{AOM}) /$ dextran sodium sulfate (DSS)-induced caCRC [16] were evaluated to confirm whether or not SYD can inhibit caCRC through EMT regulation.

\section{Materials and methods SYD preparation}

SYD was composed of nine commonly used herbs: Radix Paeoniae Alba, Radix Angelicae Sinensis, Rhizoma Coptidis, Semen Arecae, Radix Aucklandiae, Radix Et Rhizoma Glycyrrhizae, Radix Et Rhizoma Rhei, Radix Scutellariae, Cortex Cinnamomi. The raw herbs for SYD were purchased from the affiliated Nan Fang Hospital of Southern Medical University. These were mixed in the ratio of 30:15:15:6:6:6:9:15:7.5 (dry weight). Aqueous extracts of SYD were extracted at $80^{\circ} \mathrm{C}$ by stirring for $1 \mathrm{~h}$ using 10 volumes of distilled water $(\mathrm{v} / \mathrm{m})$. The extracts were centrifuged at 1,500 $\mathrm{g}$ at room temperature. To obtain the semisolid SYD solution, the supernatant was collected and subjected to condensation under reduced pressure at $70^{\circ} \mathrm{C}$ [17]. The quality of SYD was confirmed by HPLC analysis (Additional file 1: Figures S1 and S2, Table S1). SYD was suspended again in $0.9 \%$ saline at a final concentration of $2 \mathrm{~g} / \mathrm{mL}$. The solution was stored in aliquots at $-20^{\circ} \mathrm{C}$.

\section{Animals and experimental procedure}

All procedures involving laboratory animal use were in accordance with the guidelines of the Instituted Animal Care and Use Committee of Southern Medical University. All protocols were submitted and validated by Animal Care Ethics Committee of Southern Medical University (No. 2012-055). 6 and 8 weeks male C57BL/6 J mice weighting 15-20 g (specific pathogen-free) were obtained from the Laboratory Animal Center of Southern Medical University. The animals were maintained under controlled conditions $\left(22^{\circ} \mathrm{C}, 12-\mathrm{h} / 12\right.$-h dark/light cycle) in a conventional animal colony. There were 65 mice used in the study, 15 mice in control group, 30 in model group and 20 in SYD group. At the end of the study, there were 15 surviving mice in control group, 7 in model group and 12 in SYD group, respectively.

Procedures of induction of caCRC model by AOM and DSS was shown in Figure 1A [16]. At week 2, mice were injected with AOM $(10 \mathrm{mg} / \mathrm{kg}$, i.p.). After 1 week, 3\% DSS (International Lab, Chicago, IL, USA) was added to the drinking water for 7 days followed by 14 days of tap water for recovery. This cycle was repeated twice.

SYD $(7.12 \mathrm{~g} / \mathrm{kg})$ or equivalent normal saline was administered by gavage using a tube twice a day. The mice were killed by cervical dislocation at week 16 and the colons (from the ileocecal junction to the anal verge) were removed. After measuring the length and weight, the colons were cut longitudinally along the main axis, washed with phosphate-buffered saline $\left(p \mathrm{H} \mathrm{7.4,4}{ }^{\circ} \mathrm{C}\right)$ and 

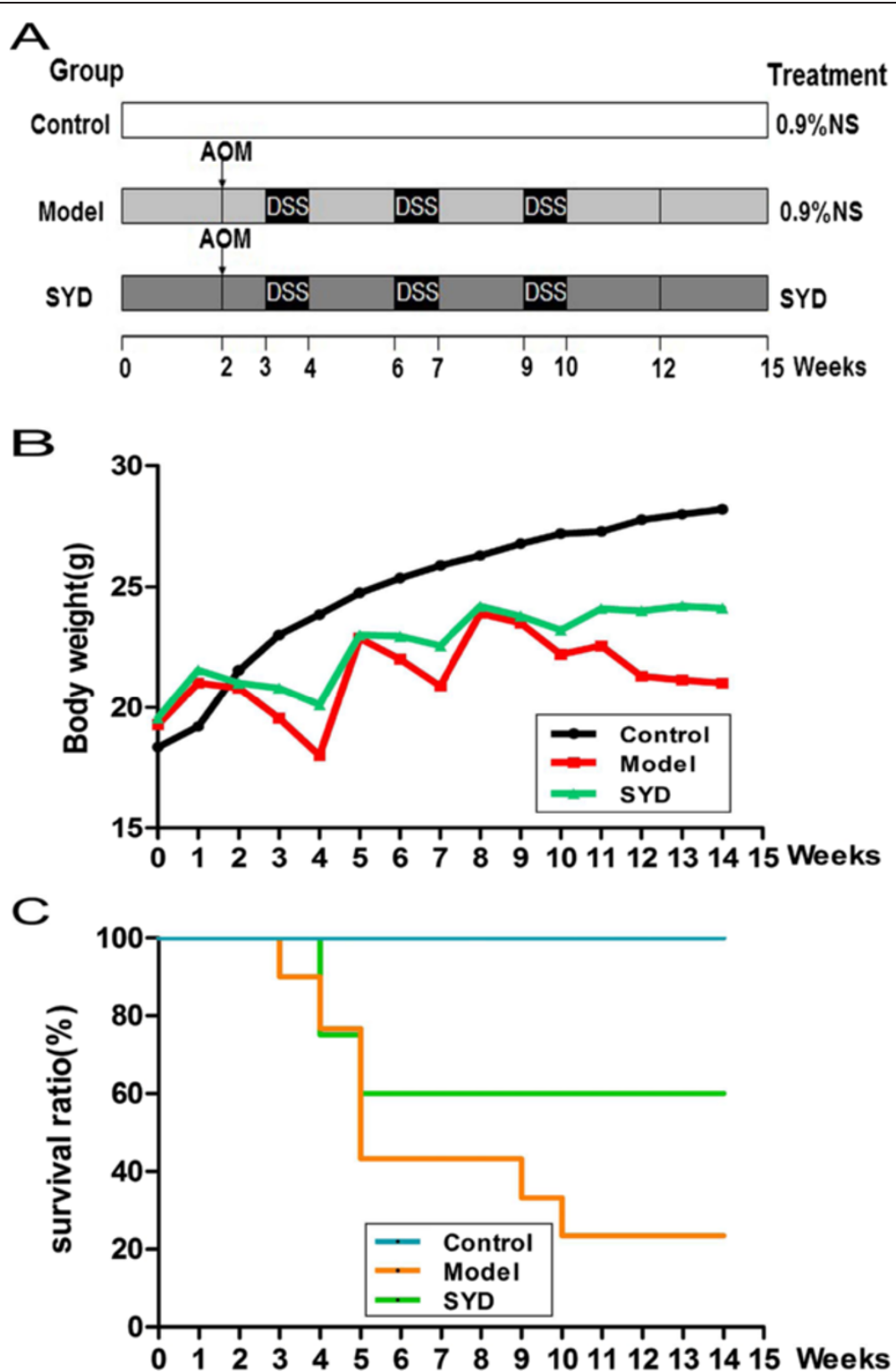

Figure 1 Effects of SYD on colitis-associated colon carcinogenesis was evaluated in C57BL/6 J mice. (A) Experimental protocol for colitis-associated colon carcinogenesis model. (B) Effect of SYD on the body weight of mice. (C) Effect of SYD on the survival ratio of mice. SYD prolonged animal survival $(P=0.032$, vs. Model). Data are presented as mean \pm SD vs. control and model.

macroscopically inspected. The number, size and location of pre-neoplastic and neoplastic lesions (dysplasia and carcinoma) in the colons were recorded based on gross examination. The size of dysplasia was measured by an ocular micrometer. After gross examination, the colons were cut into pieces at about $1 \mathrm{~cm}$ intervals. Samples were then fixed in $10 \%$ buffered formalin $(\mathrm{pH} 7.4)$ or kept in 10 volumes of RNAlater Solution (Ambion, Life technologies, Carlsbad, CA, USA). Remaining samples were flash-frozen in liquid nitrogen and stored at $-80^{\circ} \mathrm{C}$ for further immunohistochemistry, PCR and protein analysis.

\section{Reagents}

Paeonolsilatie sodium was purchased from Jinling Pharmaceutical Co., Ltd. Dimethyl sulfoxide (DMSO) and thiazolyl blue tetrazolium bromide (MTT) were purchased from Sigma-Aldrich (St. Louis, MO, USA). RPMI 1640, FBS and antibiotics were purchased from Invitrogen (Gibco, Grand Island,NY, USA). Snail homolog 1 (Drosophila) was purchased from FulenGen (Genecopoeia,USA).

\section{Cell viability assays}

MTT assay was used to analyze the effects of paeonol and SYD on cell viability in two kinds of colorectal 
adenocarcinoma cell lines SW480,HCT116. Cells were routinely maintained in RPMI 1640, supplemented with $10 \% \mathrm{FBS}$ and antibiotics $(50 \mathrm{U} / \mathrm{ml}$ of penicillin and $50 \mu \mathrm{g} / \mathrm{ml}$ streptomycin) at $37^{\circ} \mathrm{C}$ in a humidified atmosphere containing 5\% CO2. Cell number was measured on a standard microscope by manual counting of cells using a grid with an area of $0.25 \mathrm{~mm}^{2} .1 \times 10^{4}$ Cells were seeded on 96-well plates in a $100 \mu \mathrm{l}$ volume. The MTT assay was performed by addition of MTT to a final concentration of $0.5 \mathrm{mg} / \mathrm{ml}$ of medium. After $4 \mathrm{~h}$, the medium was removed, and $150 \mu \mathrm{l}$ of DMSO was added to each well. After $10 \mathrm{~min}$ of shaking at room temperature, $150 \mu \mathrm{l}$ of soluble material was placed into a new 96-well plate, and absorbance at $562 \mathrm{~nm}$ was read with a background subtraction at $660 \mathrm{~nm}$.

\section{Cell culture and transfection}

HCT116 cell line was cultured in RPMI 1640, supplemented with $10 \%$ FBS and antibiotics $(50 \mathrm{U} / \mathrm{ml}$ of penicillin and $50 \mu \mathrm{g} / \mathrm{ml}$ streptomycin) at $37^{\circ} \mathrm{C}$ in a humidified atmosphere containing 5\% CO2. For transfection,cells were seeded in a 6 -well plate $24 \mathrm{~h}$ before the experiment. The cells were transfected with Snail 1 plasmid using the Attractene reagent (Qiagen, Germany) according to the manufacture's protocol.

\section{Histopathological assessment}

For histopathological examination, formalin fixed, paraffinembedded colon tissues were cut into serial sections $(5 \mu \mathrm{m})$ and stained with haematoxylin and eosin (H\&E). Histological alternations such as dysplasia and carcinoma were verified. Assessment of dysplasia and cancer was based on the criteria set forth in the Mouse Models of Intestinal Cancers consensus report: location, presence/absence of prolapse/herniation, size, dysplasia grade, invasion level, presence of desmoplasia and presence of irregular architecture [18]. Carcinoma was defined as high-grade dysplasia of colonic mucosa which invaded beyond the muscularis mucosa and into the submucosa [16].

\section{Immunohistochemistry}

Paraffin-embedded colon sections were deparaffinized, rehydrated, and pre-treated with hydrogen peroxidase in PBS buffer. Heat-induced antigen retrieval was performed. After blocking with the appropriate antisera sections were incubated with anti-Proliferating cell nuclear antigen (PCNA) (Thermo scientific, clone PC10, 1:300), anti- $\beta$ catenin (Cell Signaling Technology, CST, clone 6B3; 1:100 dilution), anti-p53 (Leica-microsystems, clone CM5, 1:100 dilution), anti-COX-2 (Thermo scientific, 1:100 dilution), anti-E-cadherin ( CST, clone24E10, 1:200 dilution), antiN-cadherin (Millipore, clone EPR1792Y, 1:50 dilution), anti-fibronectin (Epitomics, clone F14, 1:200 dilution), anti-vimentin (CST, clone D21H3, 1:50 dilution), NF-kB
(Abcom, clone E379, 1:100 dilution), F4/80 (Santa Cruz Biotechnology, clone BM8, 1:50 dilution). After incubation with HRP-conjugated secondary antibody and tyramide amplification followed by streptavidin-HRP, positive signals were visualized by DAB kit and counter-stained with hematoxylin. Five randomly selected fields from each section were examined at a magnification of $400 \times$ and analyzed using NIS-Elements. The positive content was calculated using the following formula: positive content $(\mathrm{PC})=$ mean optical density $\times$ positive area.

\section{Western blot analysis}

Colonic tissues were homogenized in liquid nitrogen, dissolved in lysis buffer [ $7 \mathrm{~mol} / \mathrm{L}$ urea, $2 \mathrm{~mol} / \mathrm{L}$ thiourea, 4\% (w/v) CHAPS, $20 \mathrm{mmol} / \mathrm{L}$ Tris, $65 \mathrm{mmol} / \mathrm{L}$ DTT, 0.2\% pharmalyte $3 / 10$ ampholyte] supplemented with $8 \mu$ of protease inhibitor cocktail (The protease inhibitor cocktail include AEBSF hydrochloride $500 \mu \mathrm{M}$, Aprotinin $150 \mathrm{nM}$, E-64 protease inhibitor $1 \mu \mathrm{M}$, EDTA disodium $0.5 \mathrm{mM}$ and Leupetin hemisulfate $1 \mu \mathrm{M}$. Calbiochem, San Diego, CA, USA). Samples were then centrifuged at 15,000 $\mathrm{g}$ for $30 \mathrm{~min}$ at $4^{\circ} \mathrm{C}$. Protein concentrations were determined by modified Bradford assay and resolved by SDS-PAGE, transferred to PVDF membranes and blocked in 5\% non-fat milk in Tris-buffered saline (TBST, $100 \mathrm{mM} \mathrm{NaCl}, 50 \mathrm{mM}$ Tris, $0.1 \%$ Tween-20, pH 7.5). Membranes were incubated overnight with primary antibodies [anti-PCNA (CST, clone PC10, 1:1000 dilution), anti- $\beta$-catenin (CST, clone 6B3, 1:1000 dilution), anti-p53 (CST, clone 1C12, 1:1000 dilution), or anti-COX-2 (CST, clone D5H5, 1:1000 dilution), anti-E-cadherin (CST, clone 24E10, 1:1000 dilution), antiN-cadherin (Millipore, clone EPR1792Y, 1:50000 dilution), anti-Vimentin (CST, clone D21H3, 1:1000 dilution), antiSnail (CST, clone C15D3, 1:1000 dilution)] at $4^{\circ} \mathrm{C}$. This was followed by incubation with horseradish peroxidase (HRP) conjugated secondary antibodies. Protein bandings were visualized with enhanced chemiluminescence reagents (ECL, GE Healthcare Bio-science, Uppsata, Sweden). The images were captured with a CCD system (imagestation 2000 MM, Kodak, Rochester, NY, USA). Quantitative analysis of signals was performed using Molecular Imaging Software Version 4.0, provided by Kodak 2000 MM System. The optical density was normalized by $\beta$-actin.

\section{Cytokine measurement by multiplex immunoassay}

The levels of interleukin-1 $\beta$ (IL-1 $\beta$ ), IL- 6 and TNF- $\alpha$ in the serum were measured using mice cytokine multiplex kit (Millipore, Billerica, MA, USA). Quantification of cytokines was performed using the Luminex system (Austin, TX, USA) [19].

\section{Statistical analysis}

Each experiment was repeated at least three times. Data were presented as mean \pm SD. All data were analyzed using 
SPSS statistical package (version 13.0, SPSS Inc, Chicago, IL, USA). Survival rate was analyzed with Kaplan-Meier survival analysis. Data between two groups were compared with 2-independent samples tests. Ranked data were analyzed by nonparametric test (K Independent Samples Test). Mean values of data from more than 3 groups were analyzed by one-way analysis of variance (ANOVA). A value of $P<0.05$ was considered as statistically significant.

\section{Result \\ SYD increased the survival rate of mice treated with AOM/DSS}

Body weight loss and bloody stools were observed in mice acutely exposed to DSS. These symptoms were relieved during the recovery period (Figure 1B). The colon weight was increased and the length was shortened significantly in the mice that received both AOM and DSS compared with the control mice (Table 1). The significant increases in colon weight and colon length ratio were caused by apparent mucosal thickening. SYD substantially ameliorated the body weight fluctuation and mucosal thickening. The Kaplan-Meier survival curves showed that SYD significantly increased the survival rate of the mice (Figure 1C).

\section{SYD reduced the incidence and multiplicity of colonic neoplasms and oncogenic protein expression}

The colonic neoplasm formation rate was $100 \%$ in the mice treated with AOM/DSS. Neoplasms were principally distributed in the middle and distal colon (Figure 2A). The total multiplicity of colorectal neoplasms decreased by $42.8 \%$ after SYD treatment $(\mathrm{P}<0.01$, Table 2$)$. Moreover, SYD significantly retarded the development of large neoplasms (diameter $>3 \mathrm{~mm}$ ) by $59.2 \%$ (Figure 2B, Table 2). The tumour weight and tumour volume were decreased by SYD (Figure 2C). The neoplasms in the colon were mostly tubular adenoma or adenocarcinoma according to the criteria of Mouse Models of Intestinal Cancers (Figure 2D). The neoplasms was mostly high-differentiation with invasion in model group.SYD treatment could ameliorate level of differentiation and invasion of neoplasms $(P=0.041$, Table 3).

The expression levels of proliferating cell nuclear antigen (PCNA) and $\beta$-catenin increased in dysplastic and neoplastic lesions (Figure 3A and Figure 3B). Intense nuclear staining for p53 (CM5 clone: detects both mutant and wild-type forms) was detected in the neoplastic epithelium and in nondysplastic crypts, implicating the involvement of p53 mutation in our AOM/DSS-induced caCRC model [18]. The expression levels of these neoplastic markers suggested that AOM/DSS-induced caCRC phenotypically resembled human caCRC even though the expression of COX-2 was not high in adenocarcinoma (Figures 3A and 3B, Table 4).

\section{SYD and Paeonol inhibited CRC cell proliferation}

SYD significantly decreased cell viability in a time- and dose-dependent manner; the dose ranged from $0 \mathrm{mg} / \mathrm{mL}$ to $8 \mathrm{mg} / \mathrm{mL}$. The viabilities of SW480 and HCT116 cells decreased to $50.2266 \%$ and $53.6704 \%$ after 24 h of treatment with $2 \mathrm{mg} / \mathrm{mL}$ SYD (Figure 4A). Paeonol, an ingredient of Radix Paeoniae Alba, significantly decreased cell viability in a time-and dose-dependent manner; the dose ranged from $0 \mathrm{mM} / \mathrm{L}$ to $0.8 \mathrm{mM} / \mathrm{L}$. The viabilities of SW480 and HCT116 cells decreased to $48.0659 \%$ and $51.3992 \%$ after $48 \mathrm{~h}$ of treatment with $0.4 \mathrm{mM} / \mathrm{L}$ Paeonol (Figure 4B).

\section{SYD and Paeonol decreased oncogenic proteins in CRC cells} SYD and Paeonol decreased the expression levels of PCNA, $\beta$-catenin, 553 , and COX-2 in CRC cells in a dose-dependent manner. (Figure 5A and Figure 5B, Table 5 and Table 6).

\section{SYD inhibited Snail-induced EMT}

E-cad was moderately expressed in the epithelial cells of the control group but was downregulated in the epithelial cells of the model group. $\mathrm{N}$-cadherin $(\mathrm{N}$-cad) and fibronectin were strongly expressed and vimentin was moderately expressed in the model group, suggesting the occurrence of EMT (Figures 6A). SYD significantly increased the expression of E-cad and decreased the expression of $\mathrm{N}$-cad, fibronectin, and vimentin (Figures 6A, Table 4). Western blot analysis further confirmed the effects of SYD on the expression of E-cad, N-cad, and vimentin. Snail was upregulated in the model group, and it was downregulated by SYD (Figure 6B, Table 4).

Table 1 Colon and spleen assessment in mice

\begin{tabular}{|c|c|c|c|c|c|}
\hline \multirow[t]{2}{*}{ Group } & \multicolumn{3}{|c|}{ Colon } & \multicolumn{2}{|c|}{ Spleen } \\
\hline & Weight(g) & Length(cm) & W/L ratio & Weight(g) & SW/BW ratio \\
\hline Control $(n=15)$ & $0.23 \pm 0.022$ & $9.14 \pm 0.628$ & $0.02 \pm 0.003$ & $0.07 \pm 0.005$ & $0.003 \pm 0.0002$ \\
\hline Model $(n=7)$ & $0.54 \pm 0.059^{\Delta}$ & $5.75 \pm 0.477^{\Delta}$ & $0.09 \pm 0.008^{\Delta}$ & $0.35 \pm 0.036^{\Delta}$ & $0.018 \pm 0.0019^{\Delta}$ \\
\hline $\operatorname{SYD}(n=12)$ & $0.37 \pm 0.049^{*}$ & $7.56 \pm 1.133^{\#}$ & $0.05 \pm 0.003^{*}$ & $0.18 \pm 0.061^{*}$ & $0.007 \pm 0.0025^{*}$ \\
\hline
\end{tabular}

*: P< 0.01 VS Model; $:$ : $<0.05$ VS Model.

$\Delta: \mathrm{P}<0.01$ VS Control. 
A

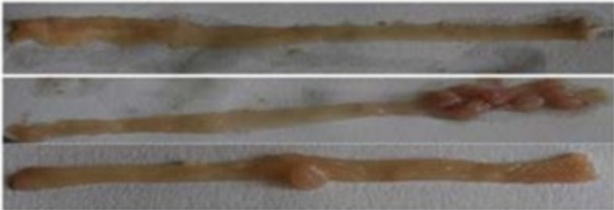

Control

Model

SYD

B

$1-3 \mathrm{~mm}$

$<1 \mathrm{~mm}$
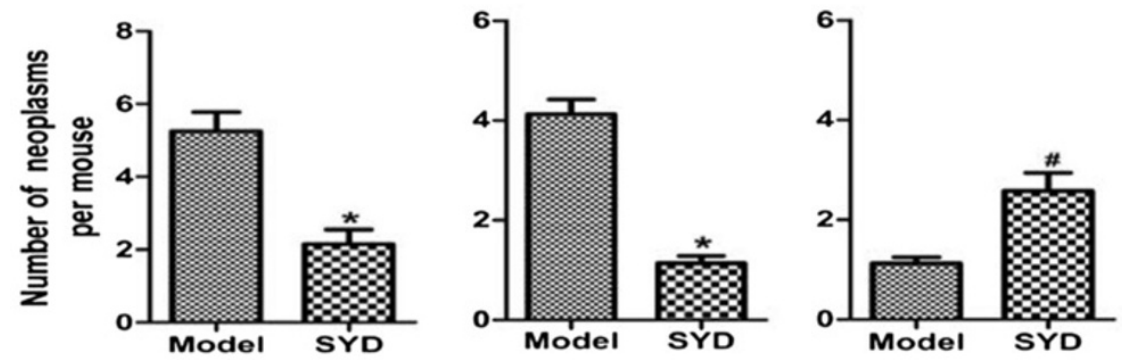

C
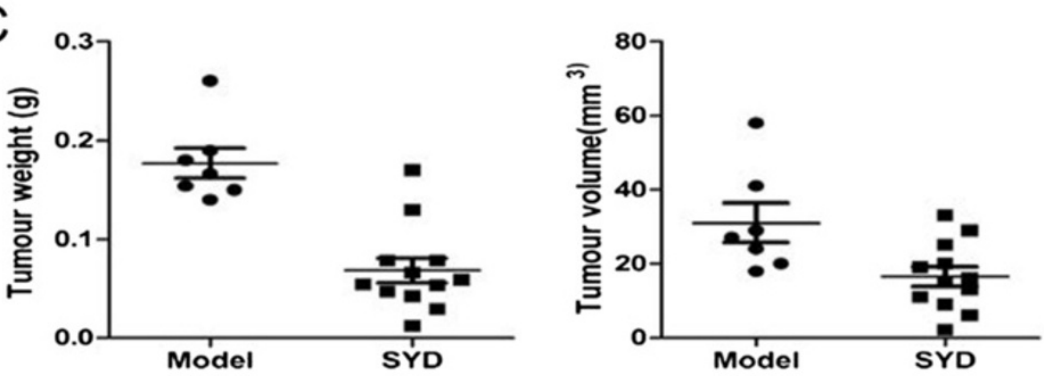

$\mathrm{D}$


Figure 2 Effects of SYD on the burden of colonic neoplasms. (A) Microscopic view of colon in mice. (B) Effect of SYD on colonic neoplasm size. SYD significantly suppressed tumor growth and reduced neoplasm size. Data are presented as mean \pm SD. *P $<0.01$ vs. model, \# P $<0.05$ vs. model. (C) Effects of SYD on tumour weight and tumour volume in each mice. SYD significantly decreased tumour weight and tumour volume. (D) Most colorectal neoplasms were histologically consistent with tubular adenoma or adenocarcinoma. Histological studies were carried out through hematoxylin and eosin staining as previously described. (Da) Normal colon; (Db) tubular adenoma; (Dc) adenocarcinoma. $40 \times$ for all, scale bar $=100 \mu \mathrm{m}$. The analysis of differentiation and invasion is shown in Table $3(P=0.041)$.

Table 2 Number and size of neoplasms in colon in mice

\begin{tabular}{|c|c|c|c|c|}
\hline \multirow[t]{2}{*}{ Group } & \multicolumn{4}{|c|}{ Number of neoplasms } \\
\hline & Total number & $>3 \mathrm{~mm}$ & $1-3 \mathrm{~mm}$ & $<1 \mathrm{~mm}$ \\
\hline Control $(n=15)$ & $0.00 \pm 0.000$ & $0.00 \pm 0.000$ & $0.00 \pm 0.000$ & $0.00 \pm 0.000$ \\
\hline Model $(n=7)$ & $10.25 \pm 1.669^{\triangle}$ & $5.25 \pm 1.488^{\Delta}$ & $4.13 \pm 0.835^{\Delta}$ & $1.13 \pm 0.354^{\Delta}$ \\
\hline $\operatorname{SYD}(n=12)$ & $5.86 \pm 1.574^{*}$ & $2.14 \pm 1.069^{*}$ & $1.14 \pm 0.378^{*}$ & $2.57 \pm 0.976^{\#}$ \\
\hline
\end{tabular}

*: $\mathrm{P}<0.01$ VS Model; ${ }^{\#}: \mathrm{P}<0.05$ VS Model.

$\triangle: P<0.01$ VS Control. 
Table 3 Analysis of differentiation and invasion

\begin{tabular}{lcccc}
\hline Group & \multicolumn{4}{c}{ Differentiation and invasion (number) } \\
\cline { 2 - 5 } & PD & MD & HD-I & HD-NI \\
\hline Model $(n=7)$ & 0 & 0 & 7 & 0 \\
SYD $(n=12)$ & 0 & 1 & 4 & 7 \\
\hline
\end{tabular}

PD: poor differentiation; MD: middle differentiation.

HD-I: high differentiation and invasion.

HD-NI: high differentiation and noninvasion.
Overexpression of Snail, a transcription factor crucial in EMT, induced the upregulation of N-cad and vimentin. SYD and Paeonol decreased the expression of $\mathrm{N}$-cad induced by Snail overexpression. (Figure $5 \mathrm{C}$, Table 5 and Table 6)

\section{SYD decreased serum cytokines, macrophage proliferation,} and NF-kB expression

The number of macrophages and the expression of NF- $\mathrm{kB}$ were increased significantly in the model group compared with those in the control group; SYD counteracted these

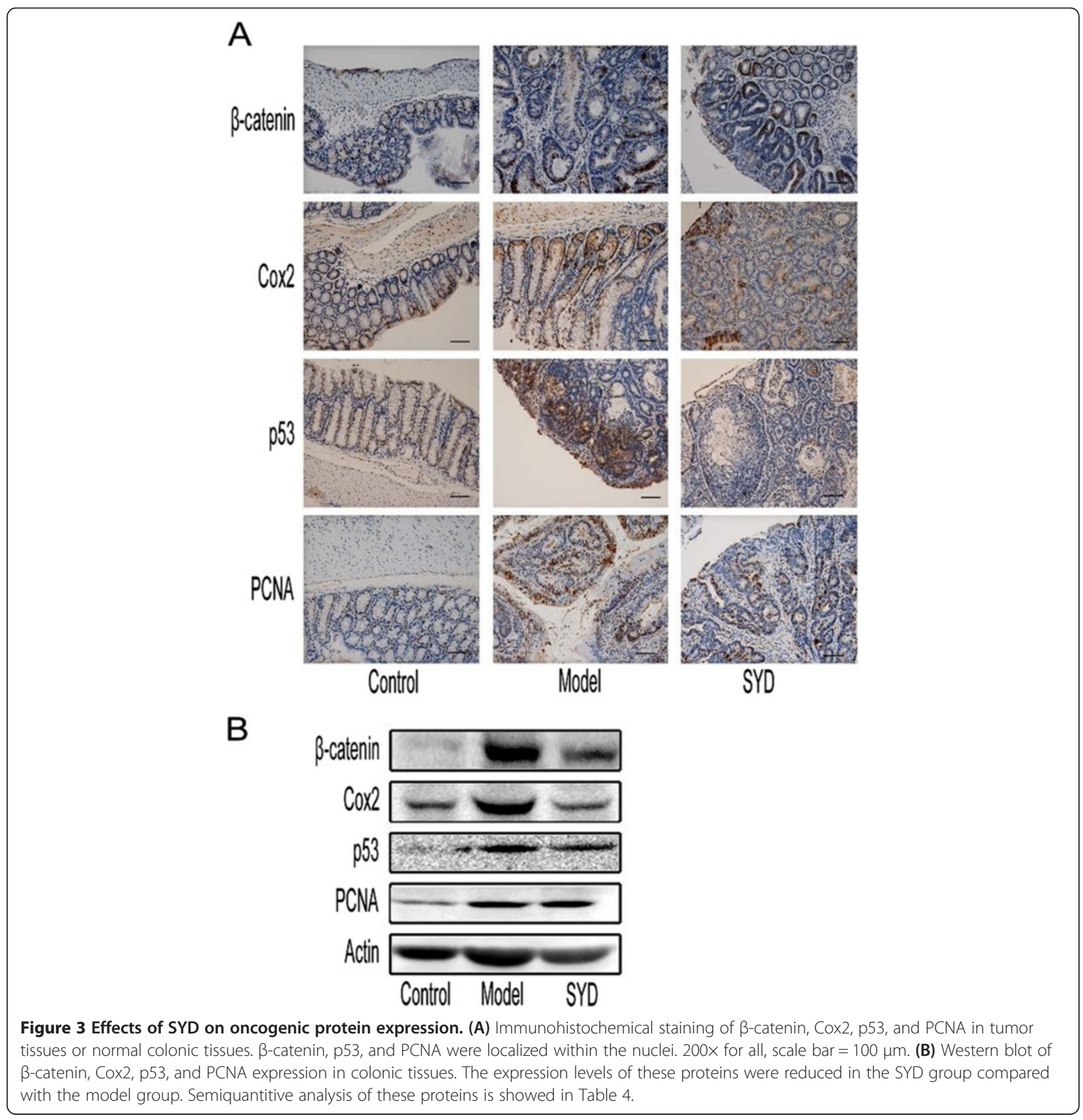


Table 4 Semiquantitive analysis of IHC and WB

\begin{tabular}{|c|c|c|c|}
\hline & Control & Model & SYD \\
\hline$\beta$-catenin-IHC & $0.52 \pm 0.39$ & $4.12 \pm 1.83^{\Delta}$ & $2.23 \pm 1.92^{\#}$ \\
\hline $\mathrm{CO} 2-\mathrm{HHC}$ & $0.97 \pm 0.30$ & $6.18 \pm 2.02^{\Delta}$ & $3.06 \pm 1.53^{*}$ \\
\hline p53-IHC & $0.66 \pm 0.45$ & $6.03 \pm 2.17^{\Delta}$ & $3.33 \pm 2.07^{\#}$ \\
\hline PCNA-IHC & $1.26 \pm 0.60$ & $5.63 \pm 2.21^{\triangle}$ & $3.06 \pm 1.95^{\#}$ \\
\hline E-cadherin-IHC & $0.50 \pm 0.39$ & $0.09 \pm 0.07$ & $3.44 \pm 1.69^{\#}$ \\
\hline $\mathrm{N}$-cadherin-IHC & $0.51 \pm 0.38$ & $8.10 \pm 1.52^{\triangle}$ & $4.22 \pm 1.19^{\#}$ \\
\hline Fibronectin-IHC & $0.80 \pm 0.81$ & $7.48 \pm 2.08^{\triangle}$ & $4.14 \pm 1.59^{\#}$ \\
\hline Vimentin-IHC & $0.24 \pm 0.28$ & $4.92 \pm 1.73^{\Delta}$ & $2.84 \pm 1.46^{\#}$ \\
\hline NF-KB-IHC & $0.89 \pm 0.48$ & $8.29 \pm 1.53^{\Delta}$ & $4.69 \pm 1.83^{\#}$ \\
\hline $\mathrm{F} 4 / 80-\mathrm{HC}$ & $0.03 \pm 0.04$ & $6.05 \pm 1.61^{\Delta}$ & $3.89 \pm 1.54^{\#}$ \\
\hline$\beta$-catenin-WB & $0.008 \pm 0.006$ & $0.750 \pm 0.292^{\Delta}$ & $0.250 \pm 0.270^{\#}$ \\
\hline Cox2-WB & $0.277 \pm 0.070$ & $0.677 \pm 0.239^{\boldsymbol{\Delta}}$ & $0.307 \pm 0.074^{\#}$ \\
\hline p53-WB & $0.064 \pm 0.040$ & $0.370 \pm 0.105^{\Delta}$ & $0.165 \pm 0.073^{\#}$ \\
\hline PCNA-WB & $0.089 \pm 0.0226$ & $0.282 \pm 0.091^{\Delta}$ & $0.158 \pm 0.039^{\#}$ \\
\hline E-cadherin-WB & $0.723 \pm 0.229$ & $0.194 \pm 0.099 \boldsymbol{\Lambda}$ & $0.560 \pm 0.185^{\#}$ \\
\hline N-cadherin-WB & $0.096 \pm 0.055$ & $0.620 \pm 0.271 \boldsymbol{\Lambda}$ & $0.262 \pm 0.131^{\#}$ \\
\hline Vimentin-WB & $0.217 \pm 0.038$ & $0.583 \pm 0.200^{\boldsymbol{\Lambda}}$ & $0.290 \pm 0.110^{\#}$ \\
\hline Snail-WB & $0.085 \pm 0.037$ & $0.423 \pm 0.146^{\triangle}$ & $0.187 \pm 0.096^{\#}$ \\
\hline Claudin-1-WB & $0.018 \pm 0.017$ & $0.280 \pm 0.141^{\triangle}$ & $0.109 \pm 0.027^{\#}$ \\
\hline
\end{tabular}

*: $\mathrm{P}<0.01$ VS Model; $: \mathrm{P}<0.05$ VS Model.

$\Delta: \mathrm{P}<0.01$ VS Control; $\mathbf{A}: \mathrm{P}<0.05$ VS Control.

IHC: Immunohistochemistry; WB: Western blot. effects (Figure 7A). Serum IL-1 $\beta$, IL-6, and TNF- $\alpha$ were upregulated in the model group and were significantly inhibited by SYD (Figure 7B).

\section{Discussion}

Variations in climatic conditions, geographic locations, and harvesting, processing, and extraction methods could challenge the quality control of herbal extracts from Chinese compound prescriptions [20]. In the present study, several specific chemical markers and batch-tobatch comparison for quality controls were utilized. This strategy (i.e., formulomics) was based on liquid chromatography for chemical characterization and chemical fingerprinting of SYD [21,22]. The strict extract quality control of SYD is important to translate the TCM formula to clinical drugs [21].

Basing on the capacity of SYD to downregulate the expression of proinflammatory cytokines, such as ICAM-1 and TNF- $\alpha$, we hypothesized that SYD ameliorates caCRC by suppressing inflammation [23,24]. Repeated DSS administration causes chronic inflammation, and AOM induces the formation of O6-methylguanine upon metallic activation [25]. Therefore, DSS in combination with AOM resulted in $100 \%$ incidence of colonic neoplasms in mice in the present experiment. DSS administration caused mass death in the model group; the effect of this drug was alleviated by SYD treatment. Tumor numbers were reduced and CRC cell proliferation was inhibited by SYD.

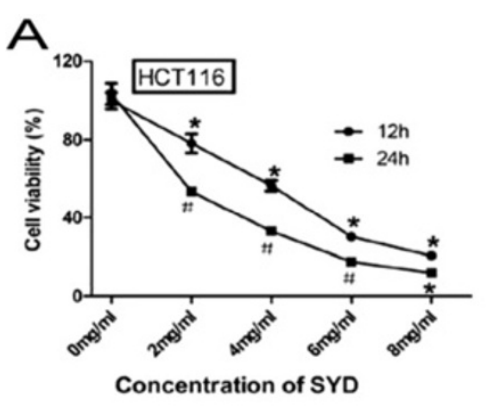

B
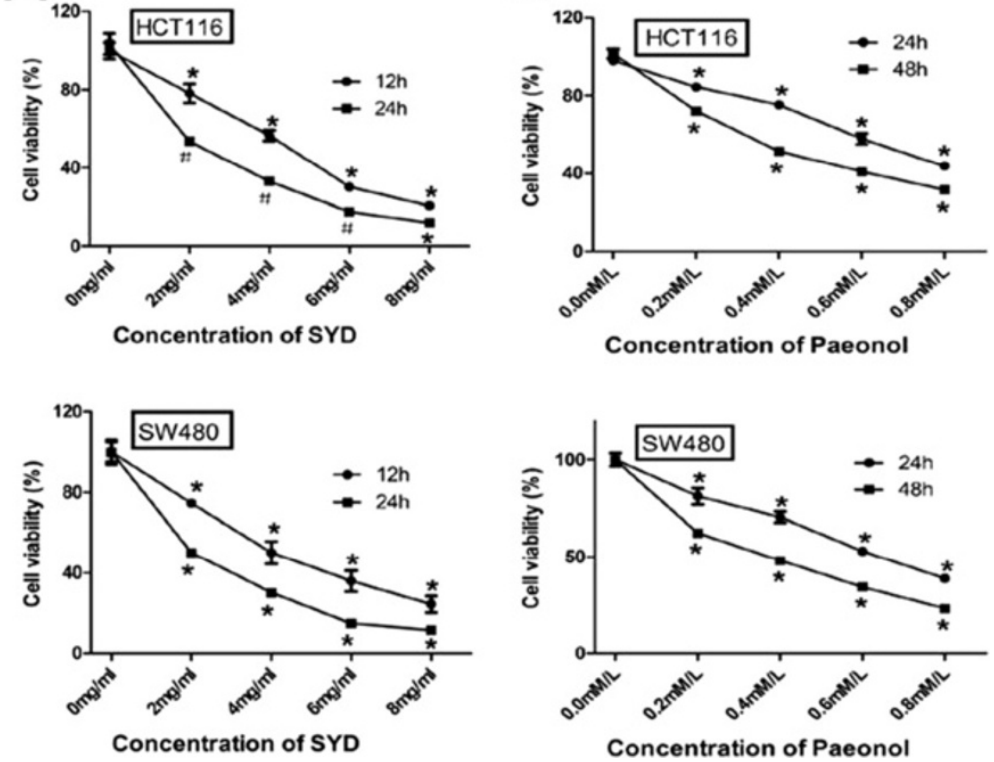

Figure 4 Effects of SYD and Paeonol on colorectal cancer cells in vitro. (A) Effects of SYD on proliferation of SW480 and HCT116. Cells were exposed to 0-8 mg/mL SYD and incubated for 12 and $24 \mathrm{~h}$. Cell viability was measured by MTT methods and values were expressed as percentage of the cell viability compared to 0 -only. ${ }^{*} \mathrm{P}<0.01 \mathrm{vs.} 0 \mathrm{mg} / \mathrm{mL}$; \#P $<0.05$ vs. 0 mg/mL. (B) Effects of Paeonol on proliferation of SW480 and HCT116. Cells were exposed to $0-0.8 \mathrm{mM} / \mathrm{L}$ Paeonol and incubated for 24 and $48 \mathrm{~h}$. Cell viability was measured by MTT methods and values were expressed as percentage of the cell viability compared to 0 -only. ${ }^{*} \mathrm{P}<0.01 \mathrm{vs} .0 \mathrm{mM} / \mathrm{L}$; $\# \mathrm{P}<0.05 \mathrm{vs} .0 \mathrm{mM} / \mathrm{L}$. 


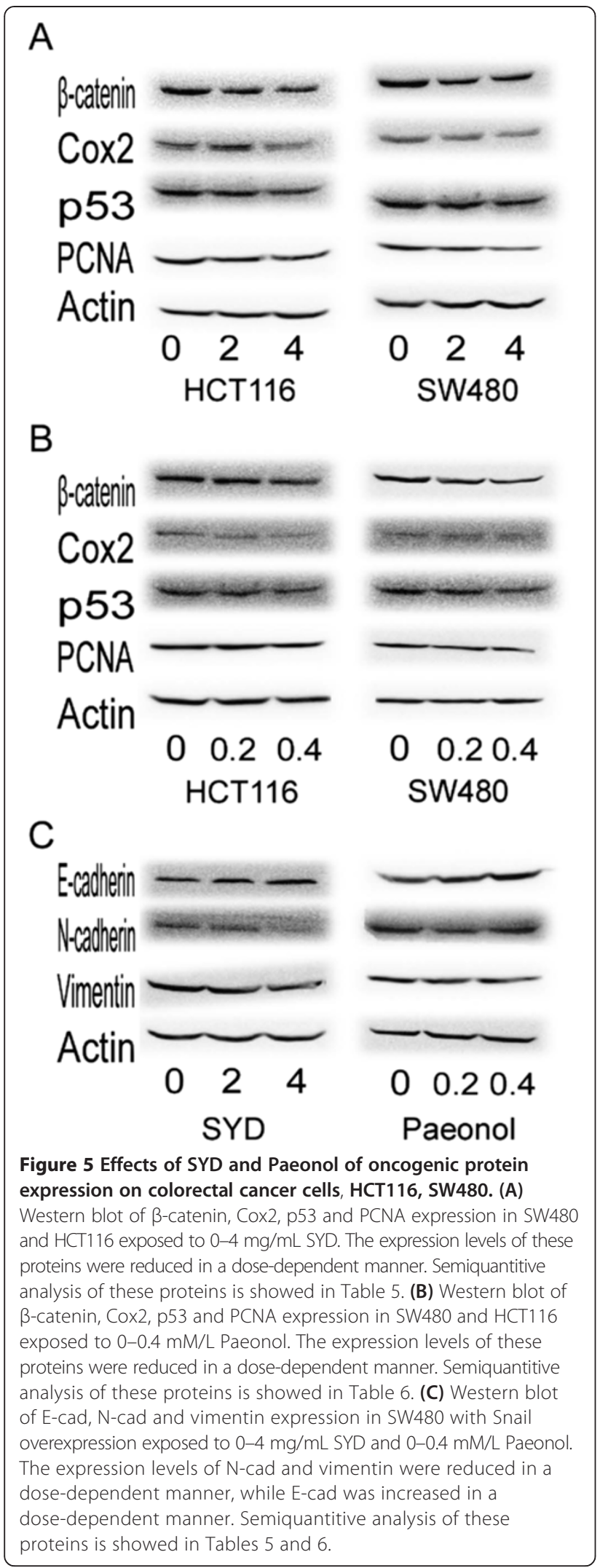

Table 5 Semiquantitive analysis of WB of SYD on HCT116 and SW480

\begin{tabular}{llll}
\hline & $\mathbf{0 ~} \mathbf{~ g} / \mathbf{m L}$ & $\mathbf{2} \mathbf{~ m g} / \mathbf{m L}$ & $\mathbf{4 ~} \mathbf{~ g} / \mathbf{m L}$ \\
\hline$\beta$-catenin-H & $0.61 \pm 0.03$ & $0.33 \pm 0.06^{*}$ & $0.193 \pm 0.07^{*}$ \\
Cox2-H & $0.24 \pm 0.03$ & $0.13 \pm 0.03^{*}$ & $0.09 \pm 0.03^{*}$ \\
p53-H & $0.52 \pm 0.06$ & $0.35 \pm 0.06^{\#}$ & $0.19 \pm 0.06^{*}$ \\
PCNA-H & $0.32 \pm 0.06$ & $0.17 \pm 0.08^{\#}$ & $0.11 \pm 0.04^{*}$ \\
$\beta$-catenin-S & $0.68 \pm 0.009$ & $0.34 \pm 0.06^{*}$ & $0.28 \pm 0.02^{*}$ \\
Cox2-S & $0.08 \pm 0.01$ & $0.02 \pm 0.01^{*}$ & $0.008 \pm 0.001^{*}$ \\
p53-S & $0.55 \pm 0.10$ & $0.34 \pm 0.08^{\#}$ & $0.25 \pm 0.09^{*}$ \\
PCNA-S & $0.32 \pm 0.12$ & $0.09 \pm 0.06^{\#}$ & $0.06 \pm 0.03^{*}$ \\
E-cadherin-SS & $0.09 \pm 0.03$ & $0.30 \pm 0.08^{\#}$ & $0.51 \pm 0.12^{*}$ \\
N-cadherin-SS & $0.22 \pm 0.05$ & $0.09 \pm 0.02^{*}$ & $0.06 \pm 0.02^{*}$ \\
Vimentin-SS & $0.53 \pm 0.06$ & $0.35 \pm 0.07^{\#}$ & $0.15 \pm 0.07^{*}$
\end{tabular}

*: P< 0.01 VS 0; ": P< 0.05 VS 0; H: HCT116; S: SW480; SS: SW480 with Snail overexpression.

These results suggested that SYD elicited antitumor effects by inhibiting CRC cell proliferation.

Increased PCNA and $\beta$-catenin expression suggested that DSS/AOM-induced neoplasm resembled human caCRC. The increase in $\beta$-catenin due to the constitutive Wnt activation for AOM induces mutations in the exon 3 of Ctnnb [25]. Wild-type p53 is a rapidly degraded protein with a low cellular level [26]; thus, the accumulation of p53 in the model group also characterizes caCRC for the early loss of p53 function [18]. Downregulation of PCNA, $\beta$-catenin, and p53 by SYD further confirmed the efficacy of SYD in DSS/AOM-induced caCRC.

EMT disrupts cell-cell adherence, causes apico-basal polarity loss, and triggers matrix remodeling to promote CRC pathogenesis and metastasis [27]. EMT endows cells

Table 6 Semiquantitive analysis of WB of Paeonol on HCT116 and SW480

\begin{tabular}{|c|c|c|c|}
\hline & $0 \mathrm{mM} / \mathrm{L}$ & $0.2 \mathrm{mM} / \mathrm{L}$ & $0.4 \mathrm{mM} / \mathrm{L}$ \\
\hline$\beta$-catenin- $\mathrm{H}$ & $0.38 \pm 0.04$ & $0.22 \pm 0.03^{*}$ & $0.13 \pm 0.04^{*}$ \\
\hline $\mathrm{Co} 2-\mathrm{H}$ & $0.17 \pm 0.07$ & $0.04 \pm 0.008^{\#}$ & $0.01 \pm 0.002^{*}$ \\
\hline $\mathrm{p} 53-\mathrm{H}$ & $0.35 \pm 0.14$ & $0.17 \pm 0.07^{\#}$ & $0.08 \pm 0.04^{*}$ \\
\hline PCNA-H & $0.37 \pm 0.09$ & $0.19 \pm 0.08^{\#}$ & $0.09 \pm 0.04^{*}$ \\
\hline$\beta$-catenin-S & $0.21 \pm 0.03$ & $0.13 \pm 0.04^{\#}$ & $0.05 \pm 0.03^{*}$ \\
\hline Cox2-S & $0.14 \pm 0.04$ & $0.05 \pm 0.01^{*}$ & $0.008 \pm 0.002^{*}$ \\
\hline p53-s & $0.48 \pm 0.18$ & $0.20 \pm 0.08^{\#}$ & $0.10 \pm 0.05^{*}$ \\
\hline PCNA-S & $0.22 \pm 0.04$ & $0.12 \pm 0.04^{\#}$ & $0.08 \pm 0.06^{\#}$ \\
\hline E-cadherin-SS & $0.04 \pm 0.03$ & $0.23 \pm 0.06^{*}$ & $0.35 \pm 0.08^{*}$ \\
\hline N-cadherin-SS & $0.42 \pm 0.06$ & $0.30 \pm 0.08^{\#}$ & $0.15 \pm 0.03^{*}$ \\
\hline Vimentin-SS & $0.37 \pm 0.05$ & $0.18 \pm 0.05^{*}$ & $0.07 \pm 0.04^{*}$ \\
\hline
\end{tabular}

*: P<0.01 VS 0; $:$ P < 0.05 VS 0; H: HCT116; S: SW480; SS: SW480 with Snail overexpression. 


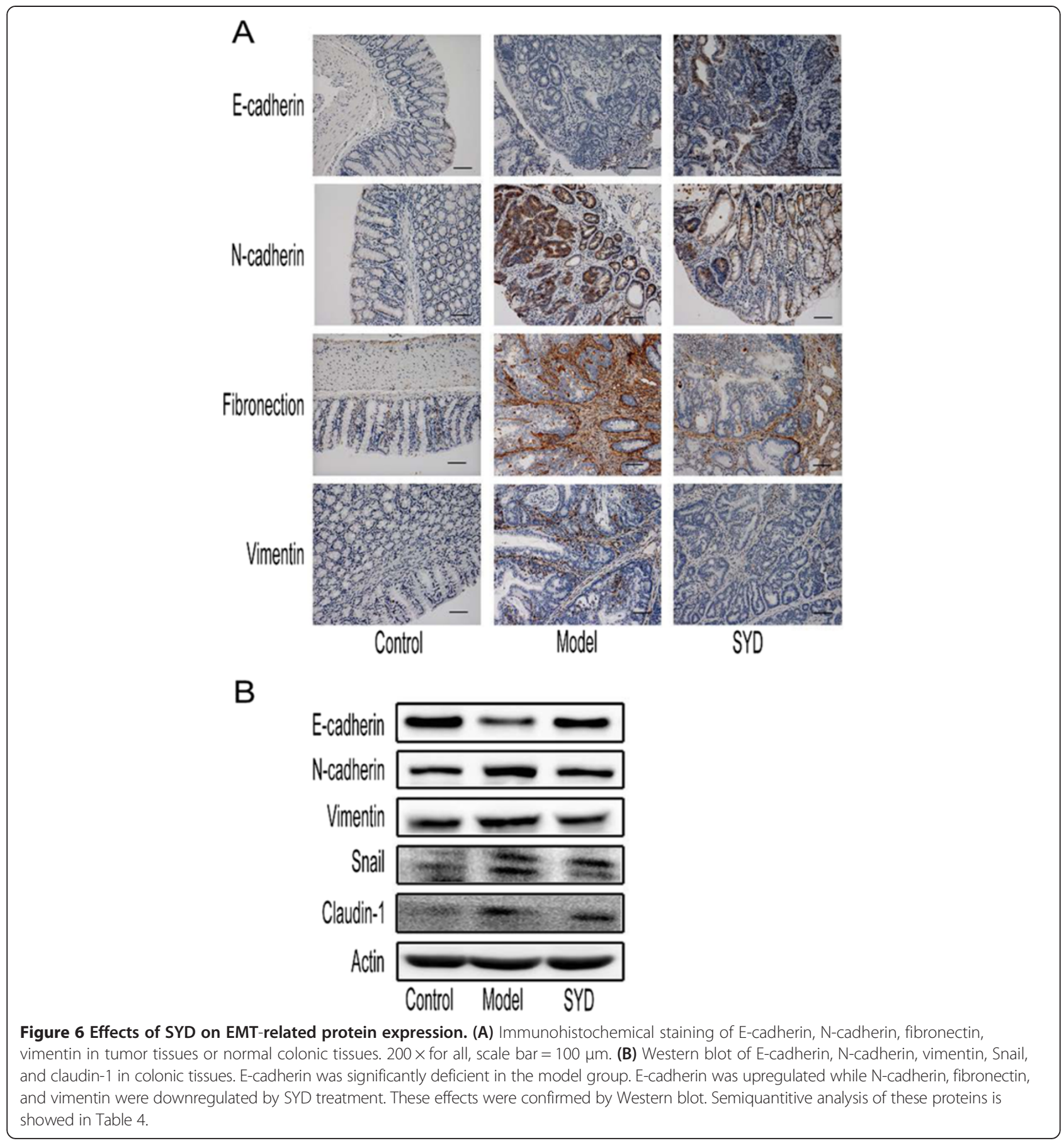

with migratory and invasive capacity, induces stem cell properties, prevents apoptosis and senescence, and contributes to immunosuppression [12]. In the present study, SYD ameliorated DSS/AOM-induced EMT, as indicated by upregulated E-cad and downregulated $\mathrm{N}$-cad, fibronectin, and vimentin. In a previous report, Snail overexpression results in dramatic changes in signaling pathways that are involved in EMT and contributes to the acquisition of stem/progenitor-like character [28]. Snail also represses epithelial gene expression and thereby promotes EMT and tumor invasion by activating the beta-catenin pathway [29]. SYD and paeonol significantly decreased Snailinduced expression of $\mathrm{N}-\mathrm{Cad}$ and vimentin. This result suggested that SYD executed its protective activity by downregulating Snail-induced EMT $[28,29]$.

The major function of SYD was to resolve colorectal inflammation through heat clearing and detoxification. Paeonol decreases lipopolysaccharide-induced TNF- $\alpha$, 


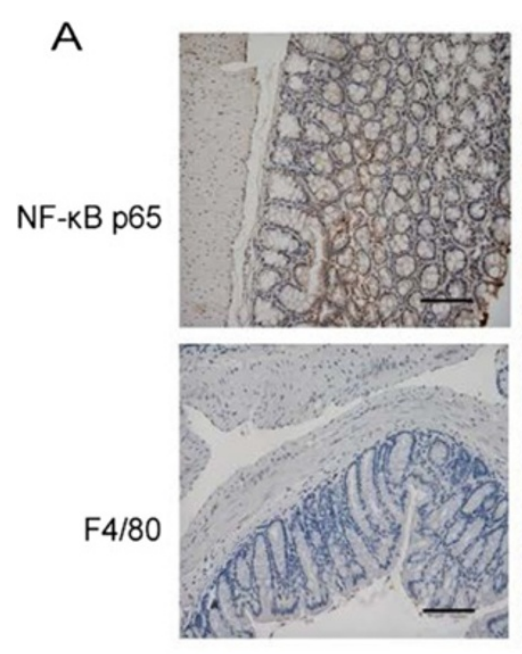

Control

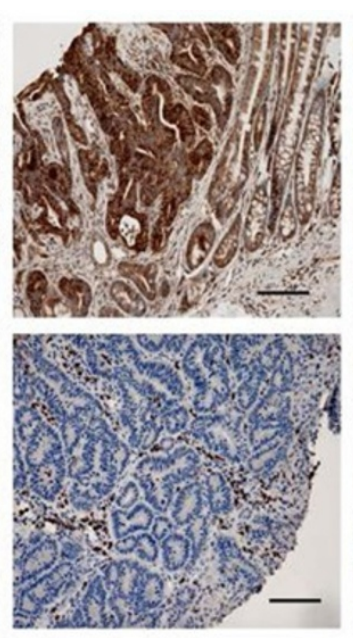

Model



SYD

B
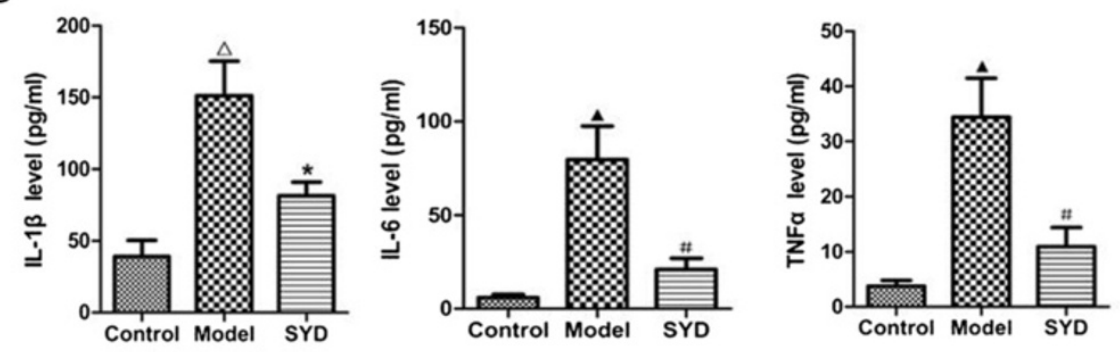

C

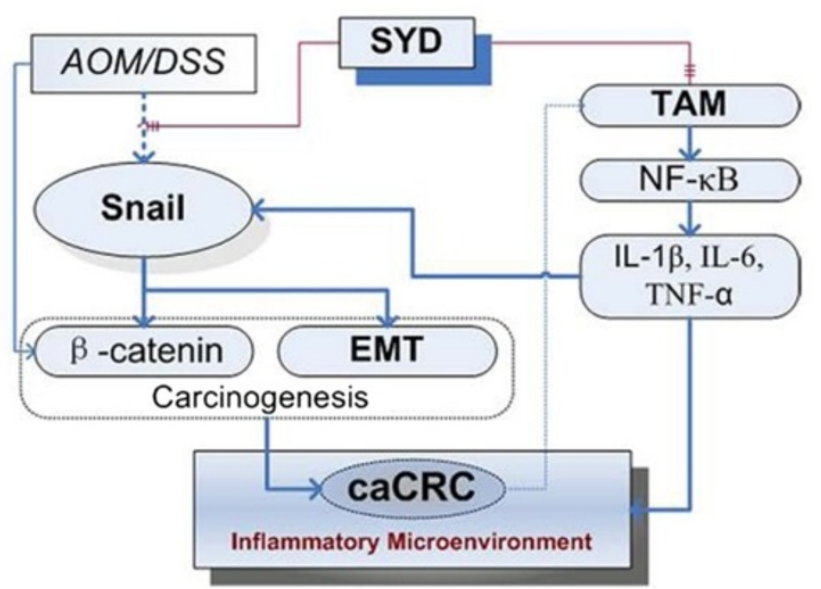

Figure 7 Effects of SYD on TAM and cytokine profile. (A) Immunohistochemical staining of NF-KB and F4/80 in tumor tissues or normal colonic tissues $.200 \times$ for all, scale bar $=100 \mu \mathrm{m}$. High expression levels of NF-KB and F4/80 were detected in the model group. SYD decreased NF-KB expression and F4/80-positive cells. Semiquantitative analysis of these proteins is shown in Table 4. (B) Luminex assay of IL-1 3 , IL-6, and TNF-a levels in serum. Serum contents of IL-1 $\beta, I L-6$, and TNF-a were reduced by SYD. Data are presented as mean \pm SD. ${ }^{*} P<0.01$ Vs. model, $\# P<0.05$ vs. model; $\triangle \mathrm{P}<0.01$ vs. control, $\mathbf{\Delta} \mathrm{P}<0.05$ vs. control. (C) A model of SYD function in caCRC.

IL-1 $\beta$, and IL-6 in RAW 264.7 cells by deactivating IkB $\alpha$ [30]. In addition, the levels of TNF- $\alpha$, IL-1 $\beta$, and IL-6 are significantly higher in CRC patients than in controls [31]. In the present study, SYD decreased the serum levels of IL-1 $\beta$, IL- 6 , and TNF- $\alpha$. Reduced IL-1 $\beta$ from macrophages may attenuate the stabilization of $\beta$-catenin and deactivate Wnt target genes in CRC cells [32]. Repressed TNF- $\alpha$ and IL-6 inhibit tumor growth in experimental models of colitis-associated cancer [33]. In the present study, macrophage infiltration and 
NF- $k B$ expression were decreased. IL-1 $\beta$, IL-6, and TNF- $\alpha$ are multifunctional NF- $\kappa B$-regulated cytokines that feature $\mathrm{\kappa B}$ or $\mathrm{kB}$-like binding motifs in their $5^{\prime}$ regulatory region $[34,35]$. Thus, we supposed that SYD can attenuate caCRC by suppressing NF- $\mathrm{kB}$ activation and related inflammatory responses [36].

Mutant p53 accumulated in inflamed colon and in cancerous glands concomitantly with NF- $\mathrm{KB}$ activation and sustained DNA damage. Mice were susceptible to chronic inflammation. However, it also greatly accelerated the inflammation-associated colon cancer under this situation [37]. TNF- $\alpha$ is a critical factor produced by macrophages to accelerate EMT [38]. This factor increases Snail protein expression and Snail nuclear translocation to initiate cancer invasion and metastasis through EMT activation [27]. EMT can be induced by activating the NF-kB pathway and enhancing Snail [39]. AOM exacerbated DSS-induced colitis to caCRC by triggering p53 mutation, $\beta$-catenin accumulation, and EMT induction upon tumor-associated macrophage (TAM) infiltration, and NF- $\kappa B$ promoted IL-1 $\beta$, IL-6, and TNF- $\alpha$ release. Therefore, SYD might ameliorate caCRC by suppressing NF- $\kappa B$ activation and cytokine-induced EMT.

\section{Conclusions}

SYD repressed IL- $1 \beta$, IL-6, and TNF- $\alpha$, thereby inhibiting Snail-induced EMT by attenuating TAM infiltration and NF-kB activation [40-42] (Figure 7C).

\section{Additional file}

Additional file 1: Figure S1. Similarity analyses of chromatographic SYD samples. The similarities of repeatability of 6 batches of SYD were from 0.937 to 0.9776 . Table S1. Comparability result of reproducibility of SYD samples. Figure S2. Determination of berberin and baicalein in SYD sample. Berberin and baicalein were matched in SYD sample.

\section{Competing interests}

The authors declare that they have no competing interests.

\section{Authors' contributions}

$X S$ and $X Y$ designed the study. $X L, J D$, and MS carried out experiments. $Z Y$ and QF performed statistical analysis. LZ, HC participated in the design of study, interpretation of results. All authors read and approved the final manuscript.

\section{Acknowledgements}

This work was supported by National Science Foundation of China (No. 81273621), Specialized Research Fund for the Doctoral Program of Higher Education (No. 20134433110007) and Baiyun District Science and Technology Program (No. 2012-KZ-81).

\section{Author details}

'Department of Traditional Chinese Medicine, Nanfang Hospital, Southern Medical University, Guangzhou 510515, China. ${ }^{2}$ The Key Laboratory of Molecular Biology, State Administration of Traditional Chinese Medicine; School of Traditional Chinese Medicine, Southern Medical University, Guangzhou 510515, China. ${ }^{3}$ Department of Pathology, Nanfang hospital, Southern Medical University, Guangzhou 510515, China. ${ }^{4}$ Department of Gastrointestinal Surgery, Guangdong General Hospital, Guangzhou 510120, China.
Received: 9 January 2014 Accepted: 9 April 2014

Published: 26 April 2014

\section{References}

1. Siegel R, Naishadham D, Jemal A: Cancer statistics, 2013. CA Cancer J Clin 2013, 63:11-30.

2. Ferlay J, Shin HR, Bray F, Forman D, Mathers C, Parkin DM: Estimates of worldwide burden of cancer in 2008: GLOBOCAN 2008. Int J Cancer 2010, 127:2893-2917.

3. Eaden JA, Abrams KR, Mayberry JF: The risk of colorectal cancer in ulcerative colitis: a meta-analysis. Gut 2001, 48:526-535.

4. Thorsteinsdottir S, Gudjonsson T, Nielsen OH, Vainer B, Seidelin JB: Pathogenesis and biomarkers of carcinogenesis in ulcerative colitis. Nat Rev Gastroenterol Hepatol 2011, 8:395-404.

5. Wang XY, Yan $X$ : [The pathogenesis features of ulcerative colitis and the pathogenetic theory of toxin impairing intestine collateral]. Zhongguo Zhong Xi Yi Jie He Za Zhi 2013, 33:410-414.

6. Xu JJ, Ji F, Chen JY, Pan F: Clinical observation of modified Shaoyao Decoction on treatment of chronic ulcerative colitis. Zhejiang J Tradit Chin Med 2007, 42:323-324.

7. Cao D, Zhou JH: Treatment of 60 ulcerative colitis patients with modified Shaoyao decoction. J Tradit Chin Med Chin Materia Medica Jilin 2005, 25:23-24.

8. Zhao XX, Ran ZB, Liu SY, Hu Q, Liu FX: The effects of Shaoyao decoction on morphology and tissue injury in ulcerative colitis rats. Tradit Chin Med Res 2008, 21:16-19.

9. Zhao XX, Guo S, Li BH, Hu Q: Experiment study on effects of Shaoyao decoction on ICAM-1, TNF-alpha and IL-10 in rats with ulcerative colitis. Chin J Tradit Med Sci Tech 2008, 15:174-175.

10. Ye JM, Deng T, Zhang JB: Influence of paeonol on expression of COX-2 and p27 in HT-29 cells. World J Gastroenterol 2009, 15:4410-4414.

11. Li M, Tan SY, Zhang J, You HX: Effects of paeonol on intracellular calcium concentration and expression of RUNX3 in LoVo human colon cancer cells. Mol Med Rep 2013, 7:1425-1430.

12. Thiery JP, Acloque H, Huang RY, Nieto MA: Epithelial-mesenchymal transitions in development and disease. Cell 2009, 139:871-890.

13. Scharl M, Weber A, Furst A, Farkas S, Jehle E, Pesch T, Kellermeier S, Fried M, Rogler G: Potential role for SNAIL family transcription factors in the etiology of Crohn's disease-associated fistulae. Inflamm Bowel Dis 2011, 17:1907-1916.

14. Flier SN, Tanjore H, Kokkotou EG, Sugimoto H, Zeisberg M, Kalluri R: Identification of epithelial to mesenchymal transition as a novel source of fibroblasts in intestinal fibrosis. J Biol Chem 2010, 285:20202-20212.

15. Zhu QC, Gao RY, Wu W, Qin HL: Epithelial-mesenchymal Transition and Its Role in the Pathogenesis of Colorectal Cancer. Asian Pac J Cancer Prev 2013, 14:2689-2698.

16. Li H, Wu WK, Li ZJ, Chan KM, Wong CC, Ye CG, Yu L, Sung JJ, Cho CH, Wang $M: 2,3^{\prime}, 4,4^{\prime}, 5^{\prime}$-Pentamethoxy-trans-stilbene, a resveratrol derivative, inhibits colitis-associated colorectal carcinogenesis in mice. $\mathrm{Br} J$ Pharmacol 2010, 160:1352-1361.

17. Zhou YC, Liu B, Li YJ, Jing LL, Wen G, Tang J, Xu X, Lv ZP, Sun XG: Effects of buyang huanwu decoction on ventricular remodeling and differential protein profile in a rat model of myocardial infarction. Evid Based Complement Alternat Med 2012, 2012:385247.

18. Garrett WS, Punit S, Gallini CA, Michaud M, Zhang D, Sigrist KS, Lord GM, Glickman JN, Glimcher LH: Colitis-associated colorectal cancer driven by T-bet deficiency in dendritic cells. Cancer Cell 2009, 16:208-219.

19. Cai HB, Sun XG, Liu ZF, Liu YW, Tang J, Liu Q, Ji BM, Song YH, Zhou YC, Yang MH, Lv ZP: Effects of dahuangzhechong pills on cytokines and mitogen activated protein kinase activation in rats with hepatic fibrosis. J Ethnopharmacol 2010, 132:157-164.

20. Tilton R, Paiva AA, Guan JQ, Marathe R, Jiang Z, Van Eyndhoven W, Bjoraker J, Prusoff Z, Wang H, Liu SH, Cheng YC: A comprehensive platform for quality control of botanical drugs (PhytomicsQC): a case study of Huangqin Tang (HQT) and PHY906. Chin Med 2010, 5:1-15.

21. Lam W, Bussom S, Guan F, Jiang Z, Zhang W, Gullen EA, Liu SH, Cheng YC: The four-herb Chinese medicine PHY906 reduces chemotherapy-induced gastrointestinal toxicity. Sci Trans/ Med 2010, 2:45r-59r.

22. Sun $X G$, Lv ZP: [Formulomics: a strategy for translational medicine research of traditional Chinese medicine based on formula extraction quality control]. Pharmacol Clin Chin Materia Medica 2011, 27:120-122. 
23. Deng $\mathrm{S}, \mathrm{Hu}$ B, Shen K: Pathogenesis and treatment of colorectal cancer in traditional Chinese medicine. World Sci Tech Modernizaztion Tradit Chin Med Materia Medica 2012, 14:1858-1862.

24. Yang ZH, Yin P, Huang AS: [The Chinese medicine syndrome features of ulcerative colitisus by using fluorescence intensity of auto fluorescence imaging]. Zhongguo Zhong Xi Yi Jie He Za Zhi 2012, 32:1319-1321.

25. Greten FR, Eckmann L, Greten TF, Park JM, Li ZW, Egan LJ, Kagnoff MF, Karin $\mathrm{M}$ : IKKbeta links inflammation and tumorigenesis in a mouse model of colitis-associated cancer. Cell 2004, 118:285-296.

26. Yazlovitskaya EM, DeHaan RD, Persons DL: Prolonged wild-type $\mathrm{p} 53$ protein accumulation and cisplatin resistance. Biochem Biophys Res Commun 2001, 283:732-737.

27. Wang $H$, Wang $H S$, Zhou BH, Li CL, Zhang F, Wang XF, Zhang G, Bu XZ, Cai $\mathrm{SH}, \mathrm{Du}$ J: Epithelial-mesenchymal transition (EMT) induced by TNF-alpha requires AKT/GSK-3beta-mediated stabilization of snail in colorectal cancer. PLoS One 2013, 8:e56664.

28. Lim S, Becker A, Zimmer A, Lu J, Buettner R, Kirfel J: SNAl1-mediated epithelial-mesenchymal transition confers chemoresistance and cellular plasticity by regulating genes involved in cell death and stem cell maintenance. PLoS One 2013, 8:e66558.

29. Stemmer V, De Craene B, Berx G, Behrens J: Snail promotes Wnt target gene expression and interacts with beta-catenin. Oncogene 2008 27:5075-5080

30. Chen N, Liu D, Soromou LW, Sun J, Zhong W, Guo W, Huo M, Li H, Guan S, Chen Z, Feng $\mathrm{H}$ : Paeonol suppresses lipopolysaccharide-induced inflammatory cytokines in macrophage cells and protects mice from lethal endotoxin shock. Fundam Clin Pharmacol 2013, doi:10.1111/fcp.12019.

31. Szkaradkiewicz A, Marciniak R, Chudzicka-Strugala I, Wasilewska A, Drews M, Majewski P, Karpinski T, Zwozdziak B: Proinflammatory cytokines and IL-10 in inflammatory bowel disease and colorectal cancer patients. Arch Immunol Ther Exp (Warsz) 2009, 57:291-294.

32. Kaler $P$, Augenlicht $L$, Klampfer L: Macrophage-derived IL-1beta stimulates Wnt signaling and growth of colon cancer cells: a crosstalk interrupted by vitamin D3. Oncogene 2009, 28:3892-3902.

33. Yang L, Parkin DM, Li LD, Chen YD, Bray F: Estimation and projection of the national profile of cancer mortality in China: 1991-2005. Br J Cancer 2004, 90:2157-2166.

34. Oshima H, Oshima M: The inflammatory network in the gastrointestinal tumor microenvironment: lessons from mouse models. J Gastroenterol 2012, 47:97-106

35. McDonald PP, Bald A, Cassatella MA: Activation of the NF-kappaB pathway by inflammatory stimuli in human neutrophils. Blood 1997, 89:3421-3433.

36. Bak YK, Lampe JW, Sung MK: Dietary supplementation of glucosamine sulfate attenuates intestinal inflammation in a mouse model of experimental colitis. J Gastroenterol Hepatol 2013. doi: 10.1111/jgh.12485.

37. Cooks T, Pateras IS, Tarcic O, Solomon H, Schetter AJ, Wilder S, Lozano G, Pikarsky E, Forshew T, Rosenfeld N, Harpaz N, Itzkowitz S, Harris CC, Rotter V, Gorgoulis VG, Oren M: Mutant p53 prolongs NF-kappaB activation and promotes chronic inflammation and inflammation-associated colorectal cancer. Cancer Cell 2013, 23:634-646.

38. Bates RC, Mercurio AM: Tumor necrosis factor-alpha stimulates the epithelial-to-mesenchymal transition of human colonic organoids. $\mathrm{Mol}$ Biol Cell 2003, 14:1790-1800.

39. Tsubaki M, Komai M, Fujimoto S, Itoh T, Imano M, Sakamoto K, Shimaoka H, Takeda T, Ogawa N, Mashimo K, Fujiwara D, Mukai J, Sakaguchi K, Satou T, Nishida S: Activation of NF-kappaB by the RANKL/RANK system up-regulates snail and twist expressions and induces epithelial-to-mesenchymal transition in mammary tumor cell lines. J Exp Clin Cancer Res 2013, 32:62.

40. Sanchez-Tillo E, Liu Y, De Barrios O, Siles L, Fanlo L, Cuatrecasas M, Darling DS, Dean DC, Castells A, Postigo A: EMT-activating transcription factors in cancer: beyond EMT and tumor invasiveness. Cell Mol Life Sci 2012, 69:3429-3456.
41. Sullivan NJ, Sasser AK, Axel AE, Vesuna F, Raman V, Ramirez N, Oberyszyn TM, Hall BM: Interleukin-6 induces an epithelial-mesenchymal transition phenotype in human breast cancer cells. Oncogene 2009, 28:2940-2947.

42. St JM, Dohadwala M, Luo J, Wang G, Lee G, Shih H, Heinrich E, Krysan K, Walser T, Hazra S, Zhu L, Lai C, Abemayor E, Fishbein M, Elashoff DA, Sharma S, Dubinett SM: Proinflammatory mediators upregulate snail in head and neck squamous cell carcinoma. Clin Cancer Res 2009, 15:6018-6027.

\section{doi:10.1186/1479-5876-12-105}

Cite this article as: Lin et al: ShaoYao decoction ameliorates

colitis-associated colorectal cancer by downregulating proinflammatory cytokines and promoting epithelial-mesenchymal transition. Journal of Translational Medicine 2014 12:105.

\section{Submit your next manuscript to BioMed Central and take full advantage of:}

- Convenient online submission

- Thorough peer review

- No space constraints or color figure charges

- Immediate publication on acceptance

- Inclusion in PubMed, CAS, Scopus and Google Scholar

- Research which is freely available for redistribution

Submit your manuscript at www.biomedcentral.com/submit
C) Biomed Central 